\title{
Creation of centre for implementation of innovation projects as economic and pedagogic tool in educational holding structure
}

\author{
Yelena Lukyanova ${ }^{1 *}$, and Daniil Gorobets ${ }^{1}$ \\ ${ }^{1}$ V.I. Vernadsky Crimean Federal University, 295007 Prospekt Vernadskogo 4, Simferopol, Republic \\ of Crimea, Russian Federation
}

\begin{abstract}
This article discloses feasible direction for improvement of training students at the structure of educational holding based on such economic and pedagogical tool as centre for implementation of innovation projects. It is substantiated that design and implementation of the modern IT-focused innovation and investment projects contribute development for professional competencies of students. And it also allows reaching better connection and correlation between theory and praxis. It is suggested basic for creation of mentioned centre according to nowadays realities.
\end{abstract}

\section{Introduction}

On the modern stage of economy development there is observed increasing of level of environment stochasticity, recession and entropy of business and institutional connections, and also are changed existing realities for functioning of economic entities at the global, national and regional planes. Search for the new forms and methods of business activities is grounded with the enforcement in requirements of international standards, growing competition and the need for new goods taking into account necessity of creating and supporting their consumer properties in the context of client-centrism, innovations, economical and social significance.

Up-to-date system of trainings for students is based on specific need of forming the detailed and objective base of knowledge, development of professional competences and solving situation tasks. At the same time there is definite disconnection of studying theory and applied praxis. This fact is also peculiar for system of educational holding. There is necessity for new approach to forming of today's professionals.

\section{Methodology and data}

There were applied general scientific and special research methods to find the solution for mentioned aim of this article, and they included quality management requirement, process approach, project management, economic, statistic and content types of analysis, experts'

\footnotetext{
* Corresponding author: lukianovahy@ukr.net
} 
estimation, and theory of constraints. It was studied theoretical and applied papers on the research topic [1-22], also official statistics data on activity of educational holdings. Article aim is substantiating the forming the centre for implementation of innovation projects (the Centre) as economic and pedagogic tool in the educational holding structure.

\section{Results}

To realize the formulated aim it implies initiating the creation of the Centre in the frames of the educational holding. In this process it must be applied interdepartmental interaction, establishing and maintaining of interdisciplinary connections. Simultaneously it also needs to take into account requirements to the Centre at the view of organizational and economic structure with use of several mechanisms for public and private partnership. The Centre should be the inner unit in the structure of the educational holding. This unit collaborates with partner external entities in the context of support of young entrepreneurs and students at the all stages of development of their innovation and investment projects - from the idea design to its commercialization.

During the Centre functioning there will be strengthened interdisciplinary connections in the process of preparation of students as professionals and it will be based on interaction of information parts of different educational courses including "Business Planning", "Balanced Scorecard", "Strategic Management", "Business Process Management", "Innovation Management", "Investment Processes", and "Economic and Mathematical Models in Economic Unit Management". Correlation of this blocks provide forming of the main practical competences in design, creating, controlling and applying of the modern profitable and socially significant projects, and also use of strategic analysis and forming of strategy for industries with high competition level. Besides it discloses administrating potential of methods of financial management, process and client-focused approaches, innovative development for assets assessment, decisions on control for working capital, investment, financing, dividends and capital structure, etc.

In the same time projects that are creating by students must be grounded on innovative technologies, unusual ideas and new ways of its implementation. There are a lot of the nowadays technologies and important directions of economic development, science and business that ought to be known by future professionals while they are studying and creating projects at the Centre at the educational holding. Even in spite of the fact that only a part of today's achievements of scientific progress and technical development can be used to the most part of existing economic entities. These achievements are wireless transmission of electricity, bio fuels, hydrogen and geothermal energy, supercapacitor, nanowire and organic solar battery, controlled thermonuclear fusion, electric vehicles and personal automatic and air transport, precooled jet and hypersonic engines, space flights without missiles (Lofstrom loop, photon engine, electromagnetic catapult, space gun, elevator and fountain), artificial intelligence, machine translation and vision, extended machine cognition, external brain amplifiers, semantic web or responsive machine, general purpose GPU, solid state drive, bulk optical memory or holographic memory, spin electronics, optical and quantum computing, quantum cryptography, wireless communication, displair, organic light-emitting diode, interferometric modulator display, laser TV, phased array optics, holography, memristor, 3D printer, thermoelectric generators, immersion to virtual reality, group robotics, molecular nanotechnology, nanorobots, powered exoskeleton, microelectromechanical systems, molecular rotors and propellers, high-temperature superconductivity and superfluidity, carbon nanotubes, metamaterials, "self-healing" materials, programmable matter, quantum dot, air crystals and others. 
Students must notice correlations in suggested project innovations with relevant and priority directions in development of region and industry; also they mark specific interrelations with peculiar regulatory documents. In the result there will be reached execution of client-focused production, regional progress and achieving requirements of environmental management, sustained development and lean production.

Substantiation of choice for definite direction of business projecting should have welldefined base of arguments including relevance of project, focus on suppliers' demands, originality, indication of implementation directions, and sequence of execution in the form of logic algorithm and its description including organizational and economic schemes for improving of devised idea and appropriate performers, instruments for visualization of designed product or service. The selection of project management tools, software and project presentation takes into account that during the design of projects and their subsequent implementation is used mechanism of creating the small initiative team in which roles of performers are allocated in accordance to earlier formulated tasks. Projects are managed with the guidance of PMBOK 6. Also at the stage of project initiation it is necessary to reveal economical and social, ecologic and infrastructure effects of it for location or area, and also consumers; define procedures, realization plan, standards of project management. Students ought to apply their knowledge and ability of applying of international standards as ISO $9001: 2015$, ISO $10006: 2003$, ISO $21500: 2012$, etc. In that case their activity is demanded not only in domestic economy but either abroad. When the Centre transfers from the phase of creating projects to performance of analytical functions for the demands of entrepreneurs who operates at the field of project management there is necessity to provide analysis of management maturity models (portfolio (PfM3), program (PgM3) and project (PjM3)) and determination of maturity levels (knowledge of processes, repetitive, defined, controlled and optimized processes), process areas (management control, administration of benefits, financial management, stakeholders management and others). During working with projects software must be applied for design, support and implementation of projects such as Primavera P6 EPPM, MS Project, Asta Powerproject, Tilos, Bentley, Deltek Acumen, CostOS, Spider Project, Rubius Project Manager, etc.

It is need to be mentioned that efficiency improving for the projects is impossible without support of information technologies (IT) at each stage of the process of project design and implementation. Today's economic unit is more competitive when it utilizes IT, and there are three approaches to describe it. The first one displays IT as processes and methods for searching, accumulating, storage, processing, providing and dissemination of information during design and implementation of projects and also directions for its implementing. The second one discloses IT as peculiar techniques, methods and tools for applying of electronic devices in processes of realization of such functions as collecting, storing, processing, transmitting and using specific data for project realization. The third one presents IT as resources for collection, processing, storage and dissemination of information. All these approaches are valid for project management. Key characteristics of the modern IT are previously fixed structure for standards in digital data exchange, widespread use of computer storage and provision of information on the required form, transmission of information with digital technologies to unlimited distances.

IT encompasses all the resources needed to control information in project design including hardware, software and networks for creating, storage, and controlling, transmitting and receiving information. Within the project infrastructure IT improves efficiency and competitiveness of business, gives informational presence in digital environment for new reality.

Information infrastructure (II) is the system of different organizational structures and subsystems that ensure functioning and development of the information space of domestic economy, and means of its processes interaction must be actively implemented by the 
Centre. II consists of information centre, subsystems, its elements, data and knowledge banks, communication and administration centres, hardware and software for collecting, storing, processing and transmitting information, and also provides consumers access to information resources.

Nowadays it is need to pay attention to the fact that it is very important to include IT and mathematic modeling to teaching of business and management courses that must be correlated with students' activity in theoretical education and also within their praxis at the Centre. The use of the modelling helps students to improve their abstract thinking, speed of reaction and information processing. Mathematic models of social and economic processes that imply the solution for equations which include dependent and independent variables and also sought functions containing various derivatives or differentials. These models are important for business projecting in the Centre. The most known of the very models are Arrow-Debrew model, Nerlove-Arrow model, Harrod-Domar model, price-volume model, dynamic stochastic general equilibrium of Keynes, Solow-Swan model, Casagrandi-Rinaldi model, Lotka-Volterra equations and others. The forming of mathematical differential models will adapt students for practical activities, teach them to track patterns in business, find correlations of various criteria and factors, understand and follow requirements of international and domestic standards of quality assurance systems, principles and methods of developing management decisions, instructions for applying regulations and terms of technical documentation to design and implementing of projects within the Centre. Presentation of projects that were prepared ought to be in the form of exhibitions of projects with involvement of stakeholders (entrepreneurs, representatives of government agencies, etc.).

Authors made research on the interests in the creating of the Centre and investing to it (fig. 1). The results illustrate high rate of both types of interests.

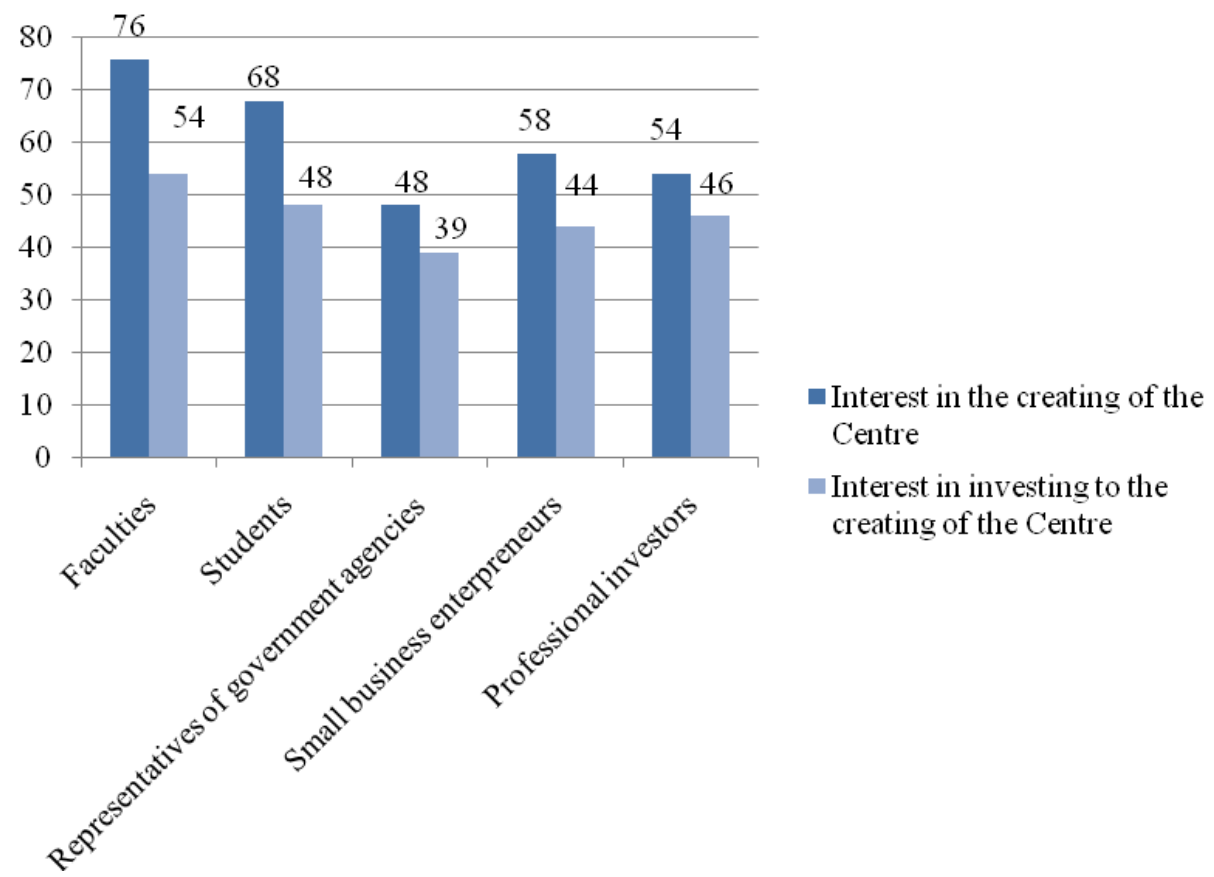

Fig. 1. The interests in the creating of the Centre and investing to it by the core focus groups (faculties, students, representatives of government agencies, small business entrepreneurs and professional investors) (\%). 
Also authors studied the growth of efficiency of the educational process with the combination of theory and praxis that provides increasing of students' attractiveness as future employees. There were taken esteems of students by themselves (1), faculties (2), small business entrepreneurs (3) and representatives of government agencies (4) according to different approaches applied in the educational courses (fig. 2).

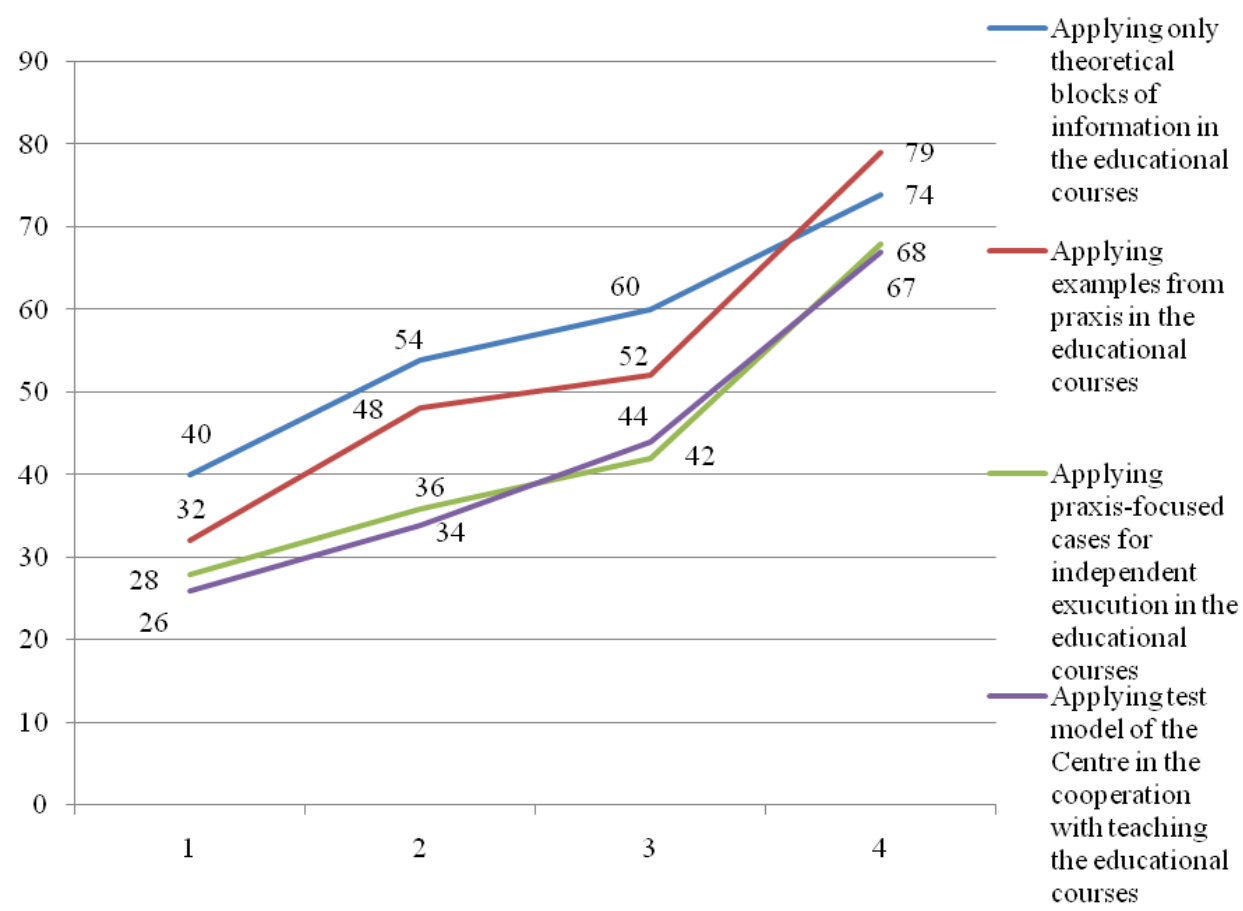

Fig. 2. The growth of efficiency of the educational process with the combination of theory and praxis that provides increasing of students' attractiveness as future employees (\%).

Applicability and reliability of the suggested projects that are made by students within the Centre taking into account relevance of projects were esteemed by different focus groups (students, faculties, small business entrepreneurs and representatives of government agencies) (fig. 3).

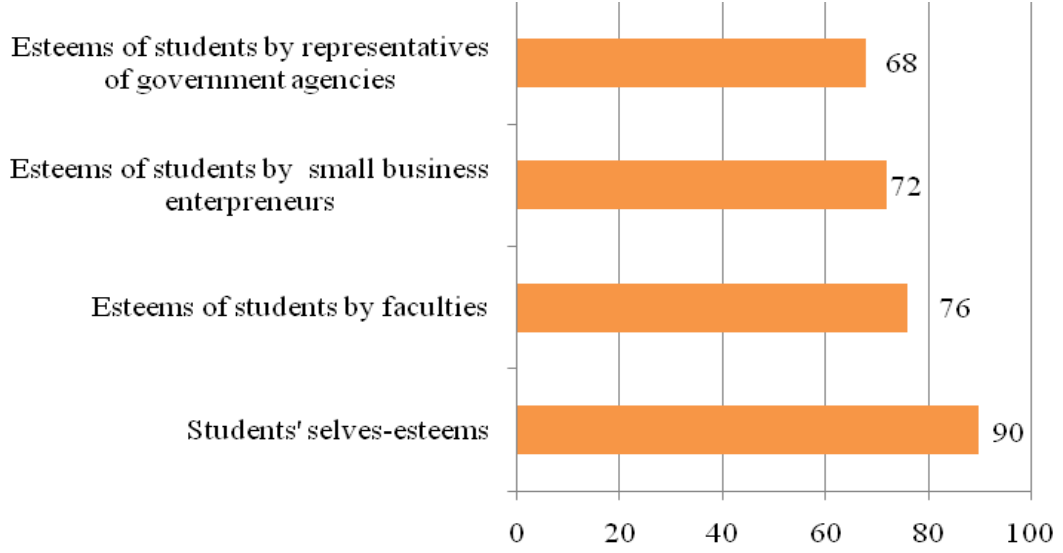

Fig. 3. Applicability and reliability of the suggested projects that are made by students within the Centre taking into account relevance of projects $(\%)$. 
The role of public-private partnership is to support and develop the idea of the Centre in the frames of the educational holding and also the assistance in finding and providing the peculiar place and equipment for it at the subsequent stages of its functioning. Business activity of the Centre will include developing of projects, business consulting and promotion of perspective startups. Total area (TA) for the Centre should be at least $900 \mathrm{~m}^{2}$, area intended for small businesses should be at least $85 \%$ of TA. The area leased to one small business entity should not exceed $15 \%$ of TA. Requirements for the equipment of the Centre include availability of at least 70 workplaces with office techniques and furniture (each workplace should have PC, access to individual printer or one in the common use, fax, copier, scanner, telephone for city line and long distance communication), Internet channel, equipped meeting and conference rooms for lectures, seminars and training sessions. Such equipment makes available providing services on leasing (also subleasing) area of the Centre for small business entities, technical operations at the part of the area of the Centre, postal secretarial services, consulting on taxation, accounting, lending, legal protection, business development, employees' trainings, access to digital information data and others.

\section{Conclusions}

Thus the use of the Centre as economic and pedagogic tool in the teaching process at the frames of the educational holding allows establishing precise relationship of theory and praxis in the skills that obtained during design and implementation of innovation and investment projects in the relevant areas of organizational and technical activities in accordance to the requirements of project management and focus on clients. Either it makes possible to converge activities of domestic business entities that implement the projects of the Centre to their partners abroad. It become real due to the implementation of the projects ideas takes into account the requirements of process management, environment management, sustainable development and lean production. Exhibitions-contests of the projects lead to intensification of network interaction within its developers, faculties, entrepreneurs and representatives of government agencies and also contribute publicprivate partnership.

It should be summarized that suggested recommendations allows optimizing of the activities of future employees with use of IT and II, improving design, implementation and estimation of the projects, responding rapidly to changes in demands of consumers, improving operations based on the approach of theory of constraints defining the toppriority locations for transformations, applying client-focused and process approaches to the activities of the Centre and its partners, developing its competitive potential, increasing competitiveness, and making correspondence to requirements of modern standards.

\section{References}

1. P. Akhavan, N. Ale Ebrahim, M.A. Fetrati, A. Pezeshkan. Scientometrics, 107(3), 1-16 (2016)

2. M.A. Allan. The International Review of Research in Open and Distributed Learning, 5(2) (2004)

3. A. Amoozegar, R. Khodabandelou, N. Ale Ebrahim. International Journal of Information Research and Review, 5(2), 5352-5359 (2018)

4. W. Boston, S.R. Diaz, A.M. Gibson, P. Ice, J. Richardson, K. Swan. Journal of Asynchronous Learning Networks, 14(1), 3-18 (2010) 
5. A. Bozkurt, E. Ozbek, S. Yilmazel, E. Erdogdu, H. Ucar, E. Guler. The International Review of Research in Open and Distributed Learning, 16(1), 1-19 (2015)

6. J.M. Ferguson, A.E. DeFlice. International Review of Research in Open and Distance Learning, 11(2), 73-84 (2010)

7. L. Harasim. The Internet and Higher Education, 3(1), 41-61 (2000)

8. T.R. Liyanagunawardena, A.A. Adams, S.A. Williams. The International Review of Research in Open and Distributed Learning, 14(3), 202-227 (2013)

9. B. Means, Y. Toyama, R. Murphy, M. Bakia, K. Jones. Structure, 15(20), 1-94 (2009)

10. D. Schoech, D. Helton. Qualitative Social Work, 1(1), 111-124 (2002)

11. M.K. Tallent-Runnels, J.A. Thomas, W.Y. Lan, S. Cooper, T.C. Ahern, S.M. Shaw, X. Liu. Review of Educational Research, 76(1), 93-135 (2006)

12. Y.Y. Lukyanova, N.P. Shamaevaю CEUR Workshop Proceedings, 2522, 100-11 (2019)

13. D.P. Bloch. Career Development Quarterly, 53 (3), 194-207 (2005)

14. S. Campbell. Encyclopedia of case study research (2012)

15. U.H. Graneheim, B.-M. Lindgren, B. Lundman. Nurse Education Today, 56, 29-34 (2017)

16. S. Peake, A. McDowall. British Journal of Guidance and Counselling, 40(4), 395-410 (2012)

17. N. Robertson, H.C. Perkins, N. Taylor. Sociologia Ruralis, 48(4), 331-350 (2008)

18. D.E. Super. Journal of Vocational Behavior, 16(3), 282-298 (1980)

19. E.M. Akhmetshin, I.A. Ilyina, V.V. Kulibanova, T.R. Teor. ComSDS 2019, 50-55 (2019)

20. E.M. Akhmetshin. Journal of Advanced Research in Law and Economics, 8(6), 16841692 (2017)

21. X.T. Huang, L. Watson. Journal of Accounting Literature, 34, 1-16 (2015)

22. Z. Rezaee. Journal of Accounting Literature, 36, 48-64 (2016) 